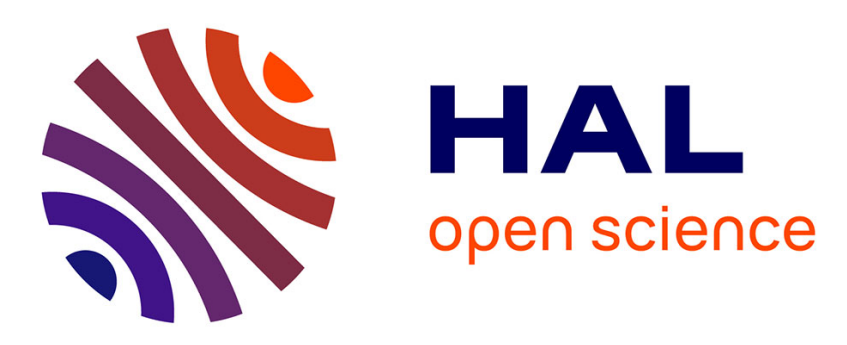

\title{
Efficient multipoles modeling for linear magnetized beads manipulations
}

Paul Kauffmann, Vincent Haguet, Gilbert Reyne, Benoît Delinchant

\section{To cite this version:}

Paul Kauffmann, Vincent Haguet, Gilbert Reyne, Benoît Delinchant. Efficient multipoles modeling for linear magnetized beads manipulations. CEFC 2010 (Conference on Electromagnetic Field Computation), May 2010, Chicago, United States. hal-00491358

\section{HAL Id: hal-00491358 https://hal.science/hal-00491358}

Submitted on 11 Jun 2010

HAL is a multi-disciplinary open access archive for the deposit and dissemination of scientific research documents, whether they are published or not. The documents may come from teaching and research institutions in France or abroad, or from public or private research centers.
L'archive ouverte pluridisciplinaire HAL, est destinée au dépôt et à la diffusion de documents scientifiques de niveau recherche, publiés ou non, émanant des établissements d'enseignement et de recherche français ou étrangers, des laboratoires publics ou privés. 


\title{
Efficient multipoles modeling for linear magnetized beads manipulations
}

\author{
P. Kauffmann ${ }^{1,2}$, V. Haguet ${ }^{2}$, G. Reyne ${ }^{1}$, B. Delinchant ${ }^{1}$ \\ ${ }^{1}$ Grenoble Electrical Engineering lab, BP 46, 38402 Saint-Martin d'Hères, France \\ ${ }^{2}$ Biopuces, CEA, Grenoble, France \\ benoit.delinchant@g2elab.grenoble-inp.fr
}

\begin{abstract}
Many Magnetic MEMS have been recently developed to manipulate spherical diamagnetic or superparamagnetic particles. Magnetic forces can be computed using the dipole method or the semi-numerical integral. However, these methods appear inaccurate or time consuming, respectively. This paper proposes a multipolar approach which provides a satisfying compromise between precision and rapidity to compute the magnetic force on linear magnetized beads. Gain in precision and CPU time will be detailed for water droplets levitating above micromagnets.
\end{abstract}

Index terms - Magnetostatics, analytical modeling, multipoles approach.

\section{INTRODUCTION}

Micro-magnets and micro-coils have been recently developed to handle particles either by attraction or repulsion according to the magnetic susceptibility of the particle. Such devices could be used e.g. for providing contamination free digital microfluidics, cells micropositioning and sorting or capturing molecules in a biological sample.

Complex micro-scale dynamic simulations with high magnetic gradients due to micro-magnets and micro-coils require specific modeling tools. A fast and precise model to compute energy and forces on linear magnetized spherical particles is presented. Thus moderate CPU time provides a precise simulation of diamagnetic, paramagnetic and superparamagnetic particles in a low magnetic field. Diamagnetic levitation of water microdroplets in air is used to demonstrate the efficiency of the method (fig. 1).
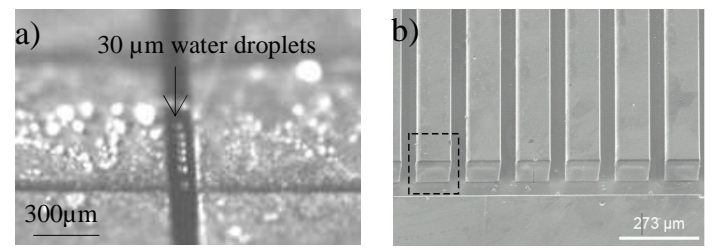

Fig. 1. a) $30 \mu \mathrm{m}$ diamagnetic droplets levitating above a magnetic groove [1], b) $50 \mu \mathrm{m}$ thick NdFeB micro-magnet deposit by sputtering.

\section{MultiPOLAR MODELING TECHNIQUE}

Magnetic force applied on a diamagnetic isotropic sphere depends on the susceptibility contrast $\Delta \chi$ between the particle and its medium. This force is the integration of $\nabla \mathrm{B}^{2}$ over the sphere volume. It can also be computed through the integration of $\mathrm{B}^{2}$ over the sphere surface:

$$
\vec{F}=\iiint_{v} \vec{\nabla} U \cdot d v=\oiint_{S}\left(U\left(S^{+}\right)-U\left(S^{-}\right)\right) \overrightarrow{d S}
$$

A magnetic multipoles model is presented. It is a transposition to magnetism of the multipoles approximation proposed by Jones for dielectrophoresis [2]. Eq. 2 details the 3 order multipolar development of the magnetic force:

$$
\begin{aligned}
& F_{i}=4 \pi \mu_{m} R^{3}\left(K^{(1)} \sum_{m=1}^{3} H_{m} \frac{\partial H_{i}}{\partial x_{m}}+\frac{K^{(2)} R^{2}}{3} \sum_{n=1}^{3} \sum_{m=1}^{3} \frac{\partial H_{n}}{\partial x_{m}} \frac{\partial^{2} H_{i}}{\partial x_{m} \partial x_{n}}\right. \\
& \left.+\frac{K^{(3)} R^{4}}{30} \sum_{o=1}^{3} \sum_{n=1}^{3} \sum_{m=1}^{3} \frac{\partial^{2} H_{n}}{\partial x_{o} \partial x_{m}} \frac{\partial^{3} H_{i}}{\partial x_{m} \partial x_{n} \partial x_{o}}+\cdots\right), \quad K^{(n)}=\frac{\mu_{p}-\mu_{m}}{n \mu_{p}+(n+1) \mu_{m}}
\end{aligned}
$$

Successive derivatives of the magnetic field can be obtained by finite difference technique. However, it may supply noise during an optimization process where dimensions are varying. If analytical expressions of the magnetic field are available, symbolic differentiation can be used. Another solution consists in automatic code differentiation which will be presented in the full paper.

\section{VALIDITY RANGE OF MULTIPOLAR APPROXIMATION}

Fig. 2 illustrates the validity range of the multipole method compared to the ratio between the radius of the droplet and the size of the magnetic groove (fig 1).

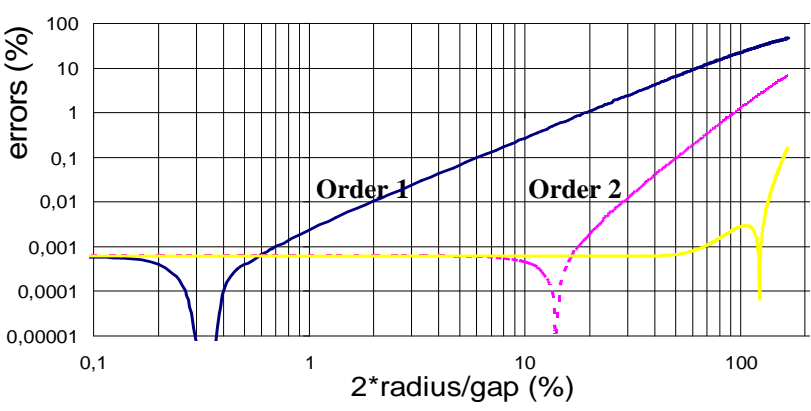

Fig. 2. Relative error due to the multipole approximation regarding droplet size relatively to the gap size between magnets.

From these results, constrained optimizations (detailed in the full paper) have been achieved very quickly for different specifications requirements. An optimization using our approach is in average about 250 times faster, keeping the same accuracy, than a numerical integration with the same gradient based algorithm.

\section{REFERENCES}

[1] H. Chetouani, C. Jeandey, V. Haguet, H. Rostaing, C. Dieppedale, et G. Reyne, "Diamagnetic levitation with permanent magnets for contactless guiding and trapping of microdroplets and particles in air and liquids," IEEE Tran. Magn., vol. 42, no 10, pp. 3557-3559, Oct. 2006

[2] T. B. Jones, "Basic theory of dielectrophoresis and electrorotation," IEEE Engineering in Medicine and Biology Magazine, vol. 22, pp. 33-42, Nov. 2003. 